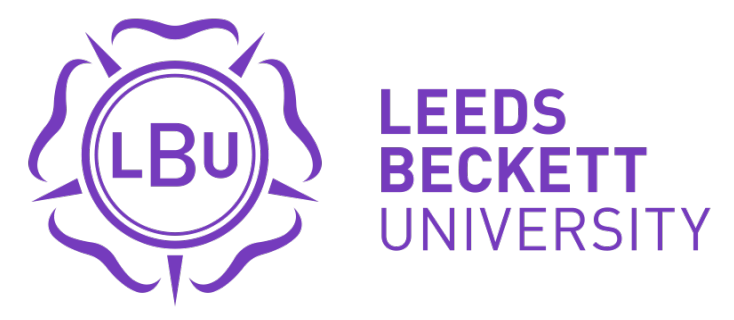

Citation:

Hoang, D and Breugelmans, E (2020) Sorry, Your Order Has a Substitution : The Effects of Substitution Policy in Online Grocery Retailing. In: Advances in National Brand and Private Label Marketing. NB\&PL 2020. Springer Proceedings in Business and Economics . Springer, pp. 145-155. ISBN 978-3-030-47763-9 DOI: https://doi.org/10.1007/978-3-030-47764-6_18

Link to Leeds Beckett Repository record:

https://eprints.leedsbeckett.ac.uk/id/eprint/7216/

Document Version:

Book Section (Accepted Version)

The aim of the Leeds Beckett Repository is to provide open access to our research, as required by funder policies and permitted by publishers and copyright law.

The Leeds Beckett repository holds a wide range of publications, each of which has been checked for copyright and the relevant embargo period has been applied by the Research Services team.

We operate on a standard take-down policy. If you are the author or publisher of an output and you would like it removed from the repository, please contact us and we will investigate on a case-by-case basis.

Each thesis in the repository has been cleared where necessary by the author for third party copyright. If you would like a thesis to be removed from the repository or believe there is an issue with copyright, please contact us on openaccess@leedsbeckett.ac.uk and we will investigate on a case-by-case basis. 


\title{
Sorry, your order has a substitution: The effects of substitution policy in online grocery retailing.
}

\author{
Dong Hoang a , Els Breugelmans ${ }^{\text {b }}$ \\ ${ }^{\text {a }}$ Leeds Beckett University, UK \\ ${ }^{\mathrm{b}}$ KU Leuven, Belgium
}

\begin{abstract}
Post-purchase out-of-stock (OOS) often happens in an online store context, where products appear to be available at the time a consumer makes an order and checks out, but then become OOS when the order is to be dispatched. To mitigate negative responses from consumers, online grocery retailers often provide consumers a substitution alternative to the OOS item. This paper investigates the effects of two substitution policies where we focus on different matching strategies of the substitution with the OOS item. In policy one, we measure the effect of matching on the dominant attribute (brand vs. flavour). In policy two, we test the effect of matching with a product from the consumers' past purchase portfolio. We investigate these two substitution policies and their interaction in two categories that differ on the level of differentiation (i.e., the degree to which distinctions are objectively measurable - vertical differentiation/VD vs. not easy to evaluate horizontal differentiation/HD). Our dependent variable is the probability to accept the substitute. The study employs a computer-simulated purchase experiment, using two product categories: margarine (VD) and cereals (HD). 2,113 UK consumers representative of general UK shopper profile participated. Findings show that in the margarine category where brand is the dominant attribute, the same brand substitution is more likely to be accepted than the same flavour substitution. In contrast, in the cereal category where flavour is more likely to be the dominant attribute, same flavour substitution is more likely to be accepted than same brand substitution. The results also show that, in both categories, matching the substitution product with a product from consumers' past purchase portfolio is more likely to be accepted than offering a substitute that consumers have not bought before. We also found a significant interaction between the two policy types but for cereals only. The effects of two substitution policies are mediated by perceived fairness of the substitution. The paper discusses contributions and implication for future research.
\end{abstract}

Keywords: online grocery, online retailing, out-of-stock, substitution

\section{Introduction}

Product unavailability is a common problem that consumers face when grocery shopping both in store and online. In a physical store context, an out-of-stock (OOS) product becomes immediately apparent in the purchase decision process and consumers can react straight away on how to deal with the OOS situation (Campo et al., 2000, Sloot et al., 2005). In an online store context, where the phase of purchase (ordering) and receiving (pick up/delivery) are separate, an OOS is not always apparent to the consumers. Products may appear to be available on the online shelves at the time a consumer makes an order and checks out, but then become OOS when the order is picked up/delivered. Market surveys have shown that post-purchase OOS is one of the top three drawbacks of the shopping experience for online grocery shoppers in the UK (Poulter, 2011). When such post-purchase OOS occurs, online grocery retailers often replace the OOS item with an alternative as a substitute, leaving customers the option of either accept or reject the substitution at the doorsteps when receiving the product at home (Severs, 2014). The goal of such a substitution policy by retailers is to mitigate consumers' dissatisfaction with the online grocery retailers' service (Cocozza, 2019) and to prevent loss of sales. The distinctive nature of post-purchase OOS compared to prior-to-purchase OOS in an online store context is that online retailers can follow a strategy to select a suitable substitution to the OOS item on behalf of the customers.

The choice of substitution alternative in the context of a post-purchase OOS poses two important challenges for an online grocery retailer (Cocozza, 2019). Firstly, the remaining assortment to choose a substitution alternative from is oftentimes large, and existing literature has not offered a full understanding of which product attributes are determinant in selecting a substitution alternative in a given product category. Is it more important to select a substitution alternative that is similar on flavour or on brand? If you select the same flavour of another brand, does it matter whether the substitution is a NB or PL? Does the determining attribute for the substitution alternative, flavour or brand, depend on category characteristics? And, how (if at all) can online retailers that have the record of consumers' past purchases, use this as a decisive factor in their substitution policy? Secondly, retailers must be wary of consumers' reactance towards the substitution if the selected substitution alternative is incongruent with their consideration set (Fitzsimons and Lehmann, 2004) or when shoppers are suspicious of retailers recommending higher priced items (Breugelmans et al., 2006). As such, retailers should question what effects their substitution policies have on consumers' fairness perceptions.

Our first objective is to investigate consumers' behavioural response to two substitution policies on the probability to accept the alternative. In a first polity, we test the effects of (not) selecting the dominant attribute by manipulating a substitution alternative that matches the OOS item on brand vs. flavour. Note that matching on brand implies another flavour whereas matching on flavour implies suggesting another brand. For the latter, we also examine the difference between suggesting the same flavour of another national brand (NB) vs. the same flavour of the private label (PL). In a second policy, we explore the effect of offering a substitution alternative that was bought by consumers in the past. Our second objective is to compare whether the effects of the two substitution policies and their interaction are the same across two product categories that vary on the differentiation strategy (focus on the price/quality dimension vs. the flavour/variety dimension). We speculate that the latter may be instrumental in determining the dominant attribute. Our third objective is 
to examine the underlying mechanism via the role of perceived fairness of the policies and its effects on the probability of consumers' acceptance of the substitute.

\section{Conceptual framework}

Previous research has shown that when considering an alternative, consumers tend to focus on a number of factors such as: a) whether the alternative is similar to the intended to purchase items (Campo et al., 2003); b) whether they are familiar with or have experienced the alternatives in the past (Bronnenberg and Vanhonacker, 1996); and c) the perceived equity in terms of cost, quality and value of the alternatives compared to the OOS item (Xia et al., 2004). Drawing on these key factors, we develop a conceptual framework as follow, where a) and b) are captured by policy 1 and 2 respectively while c) is controlled for in the analyses.

Figure 1: Substitution policies conceptual framework

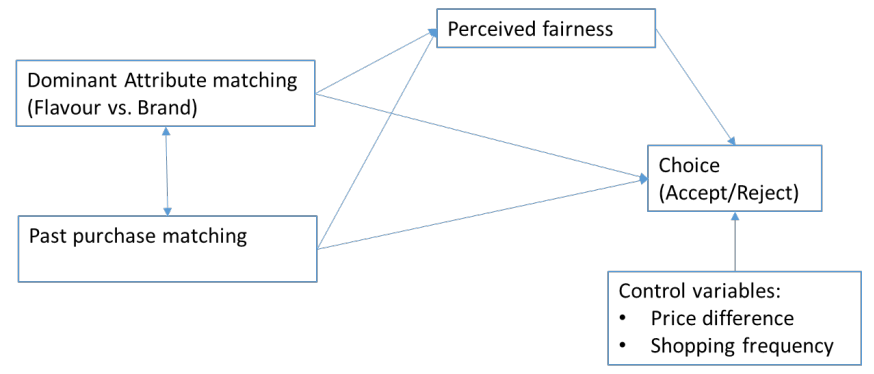

\subsection{Policy 1: Similarity of Dominant Attribute}

Similarity is defined by common attributes or characteristics between the substitution alternative and the OOS item (Tversky, 1977). Research using phantom effects has established that similar alternatives are preferred to dissimilar alternatives when a preferred (phantom) is not available (Pratkanis and Farquhar, 1992). This is because similarity reduces the cognitive effort of decision making (Fitzsimons, 2000). Thus, similarity indicates an interchangeable choice option (Tversky, 1977, Arens and Hamilton, 2016). Similarity appeals are not homogeneous amongst various attributes such as flavour, variety, brand and price (Campo et al., 2003, Breugelmans et al., 2007, Arens and Hamilton, 2016). Prior research has indeed suggested that in some product categories an attribute might carry more weight than other attributes (Batra et al., 2001). For example, some studies in food categories suggest that taste and nutrition value weight more than brand and packaging in influencing food choice (Onwezen et al., 2012). Another study also suggests that consumers optimise their choice by prioritising which attribute to consider first, either a quality-based or a type-based attribute (Shao, 2015). Hence, we expect that an alternative that is similar to the OOS item in an attribute that is seen as more dominant or important in that category will likely be more favourable than one that is similar in a less dominant or less important attribute. We speculate that what the dominant attribute is, differs across product categories.

In this research, we focus on categories that differ on the degree of differentiation. Literature on differentiation has established two differentiation strategies: horizontal and vertical differentiation (Hauser and Shugan, 1983, Sayman et al., 2002). Horizontal differentiation (HD) suggests that no brand is uniformly better than the other bands, hence, competing brands have different strengths (Hotelling, 1929, Hauser and Shugan, 1983). Products in the horizontal differentiation are differentiated in features or attributes which cannot be objectively ordered, such as colour, style, variety or flavour (no one style, colour, variety or flavour is uniformly better than another one). Differences in consumers' tastes lead to consumers buying a certain style, colour, variety or flavour and not the other (Spiller and Belogolova, 2017). Breakfast cereals is a typical example of a HD category (Hotelling, 1929, Hauser and Shugan, 1983) as it is often dominated by few brands offering a large number of flavours targeting different taste preferences (adult, kids, chocolate, honey or natural flavour etc...) (Mintel, 2018). In contrast, vertically differentiation (VD) indicates that products can be ordered because these products tend to differ on the level of quality and performance (Spiller and Belogolova, 2017). Therefore, consumers choose certain products mostly because of differences in perceptions of overall quality and price. We consider margarine as an example of a VD category, because the category has a range of national brands positioning from standard to premium while offering just one or two varieties (original or lighter/less fat) (Mintel, 2017b). Consumers tend to prefer expensive brand of margarine over the cheaper ones due to perceived superior taste quality (Orchant, 2013).

Applying this to a setting of substitution policy in an OOS situation, we expect that in a category where assortment variety is horizontally differentiated, attributes such as flavour and type are more likely to be dominant over brand. In contrast, in a category where products are mainly vertically differentiated, the brand attribute, which reflects differences in quality and price (Etgar and Malhotra, 1981) is more likely to be dominant. Considering the above, we predict that, in a HD category, substitutes are likely to be more similar if they match flavour rather than brand, while in a VD category, similarity is higher if the substitutes match on brand rather than another attribute. Thus:

Hla. In a predominantly VD category, substitution alternatives of the same brand have a higher probability of being accepted relative to substitution alternatives of the same flavour.

$H 1 b$. In a predominantly HD category, substitution alternatives of the same flavour have a higher probability of being accepted relative to substitution alternatives of the same brand.

When offering a substitution alternative that matches the flavour/type of the OOS item, retailers need to decide whether they offer the same flavour of a PL or the same flavour of a NB as substitution alternative. Retailers might be 
motivated to use the PL as the substitute because it generates higher margin than NB (CBinsights, 2018). Prior studies suggest that the strength of preference of PL may differ depending on the category (Choi and Coughlan, 2006), which is why we speculate there might be differences between predominantly VD vs. HD categories in this respect. In a VD category, consumers tend to evaluate alternatives based on brand/price and quality perception (Render and O'Connor, 1976), suggesting that a NB substitute is more preferred than a PL substitute. Indeed, the presence of a PL makes a NB become a compromise or middle option in terms of quality in the retailer's assortment (Geyskens et al., 2010). Compromise choice indicates the product obtains a relatively larger utility and choice probability (Simonson 1989). Hence, we postulate that in a VD category, same flavour NB substitution is likely to be preferred to the same flavour PL substitution. In contrast, for HD categories, retailers tend to introduce PL products that are very similar to leading NBs by making their packaging, sizes, typeface, and labelling as close as possible to the NBs in order to signal to the consumers that the PL is physically similar and has a comparable quality at a lower price than the NBs (Choi and Coughlan, 2006). As consumers' choice in a HD category depends more on taste preference of certain product flavours or types than on brand attribute, PL's mimicking strategy would make it more appealing to consumers in terms of value for money and more similar in terms of important attributes when offered as substitute. Hence, we hypothesize as follows ${ }^{1}$.

H2a. In a predominantly VD category, a private label of the same flavour as substitution alternative has a lower probability of being accepted than a national brand of the same flavour as substitution alternative.

$H 2 b$. In a predominantly HD category, a private label of the same flavour as substitution alternative has a higher probability of being accepted than a national brand of the same flavour as substitution alternative.

\subsection{Policy 2: Familiarity with past purchased item}

Literature of choice heuristics suggests that prior knowledge and experience of a product influence the types of information processed in making comparisons and choices (Wedel et al., 1998). When consumers face an OOS situation and are given a familiar substitution item, which has been purchased and consumed by the consumers in the past, they will most likely use their memory of previous experience to aid the decision (Hoeffler and Ariely, 1999). Established research suggest that the likelihood of choosing familiar products is higher than unfamiliar ones because familiarity eases the choice decision (Fitzsimons, 2000) while unfamiliar products signal uncertainty and increase complexity of the decision making process (Dhar, 1997). In addition, literature on the consideration set suggests that consumers often have a set of alternative products in mind which equally satisfy their needs (Hamilton et al., 2014). Compositions of a consideration set could include member products with varying attributes such as brands and product features like flavour or type (Roberts and Lattin, 1991, Hamilton et al., 2014). Member products may have different attribute weight but being in a consideration set indicates their overall utilities meet or exceed the consideration threshold by the consumers, hence, are likely to be purchased (Roberts and Lattin, 1991). We therefore posit that a substitution alternative, which was historically bought by a household will more likely be accepted than the one that consumers have had no experience with. Thus:

H3. In both predominantly VD and HD categories, past purchase-matching substitutions have higher probability of being accepted than non-matching substitutions.

\subsection{Interaction between both policies}

While we expect in general that product familiarity has a positive effect, there are indications in the literature that the interaction between product familiarity (policy 2) and dominant attribute similarity (policy 1) may differ between a HD vs. VD category. In a VD category where brand is expected to be the dominant attribute, consumers can evaluate a substitution alternative from extrinsic cues such as brand communication, packaging and price (Render and O'Connor, 1976). Their past purchase of certain products tends to indicate these products are of acceptable quality to the consumers (Hamilton et al., 2014). Therefore, we do not expect different past purchase-matching effects between same flavour vs. same brand substitutions. In contrast, in a HD category where flavour is expected to be the dominant attribute, consumers rely on past consumption experience to evaluate the substitution alternative (Hoeffler and Ariely, 1999). Their experience of different flavours could indicate trial and error (Drewnowski, 1997), as such, past purchase of different flavours would indicate those flavours are satisfactory. We posit that familiarity will be more important for the same flavour substitution policy compared to the same brand substitution policy. Hence:

H4a. In a predominantly HD category, past purchase-matching of the same flavour substitutions have higher probability of being accepted than past purchase-matching of the same brand substitutions.

H4b. In a predominantly VD category, there is no difference in the effect of past purchase-matching between the same flavour vs. the same brand substitutions on the probability of being accepted.

\subsection{Mediating effects of perceived fairness}

Post-purchase OOS signals a service failure of the retailer being unable to deliver the product that customers have ordered and paid for (Poulter, 2011). We argue that the underlying mechanism which partly explains consumers' decision to accept or reject the substitutes offered by the retailer lies at consumers' perception of fairness of the substitution. The mechanism which explains the role of perceived fairness rests on two accounts. Firstly, in a service failure situation like post-purchase OOS, consumers experience a loss (e.g. time, effort and motivation) (Smith et al., 1999). A fair substitution

\footnotetext{
${ }^{1}$ When testing the differential effects of a NB vs. PL substitution, we control for price differences between the substitution alternative and the OOS item, to rule out that the effects we find are driven by price perception differences rather than attribute similarity.
} 
would be the one that the consumer believes equitably makes up for the loss (Deutsch, 1985). Offering substitutions which match consumers' preference (e.g. flavour or brand) or within their choice set from past purchase likely offset that loss and positively impact on the fairness perception. Secondly, when the choice restriction occurs post purchase, consumers often expect the service provider to have adequate consideration and knowledge about their customers when resolving the service failure (Lind, 1995). Therefore, a substitution offered by the retailer is likely to be judged by the consumers on the ground of how fair the substitution is (Grewal et al., 2008). Hence, we propose:

H5. There are significant mediating effects of perceived fairness of substitution policies on the probability of being accepted.

\section{Method}

To collect data for the study, we use a computer-simulated purchase experiment that mimics a realistic online grocery store (Breugelmans et al., 2006). We test our hypotheses using two product categories: a VD category, margarine (16 SKUs) and a HD category, cereals (23 SKUs). A chi-square test of goodness-of-fit was performed to determine a dominant attribute (brand, flavour and others) in each category. The result shows brand (flavour) is significantly more important in margarine (cereals) $\left(\chi^{2} \mathrm{~m}(2)=11.918, \mathrm{p}=.003 ; \chi^{2} \mathrm{c}(2)=12.979, \mathrm{p}=.002\right) .2,113 \mathrm{UK}$ consumers representative of the general UK online grocery shoppers (Mintel, 2017a) participated in the experiment of which 959 and 1,154 shopped for margarine and cereals respectively. The procedure includes three parts: first participants answered initial survey questions in order for the data to be captured and feed into the purchase simulation in the second stage. This includes questions about what products in the assortment consumers have purchased in the past 12 months (past purchase portfolio) and their general shopping frequency (control variable). In the simulation part, participants were asked to conduct an online shopping in one of the two product categories depending on whether they have shopped with the category in the past (those who have purchased items in both categories were randomly assigned to one category). After participants select products, booked for delivery and completed their shopping, they were notified an item (margarine or cereal) was OOS and being replaced by a substitution alternative which falls in one of the 6 experimental conditions: 3 dominant attribute (same brand x same flavour NB x same flavour PL) x 2 past purchase (yes vs. no). Participants were then asked to decide if they want to accept or reject the substitution. In the flavour matching condition, we paired the product with similar flavour but from a different brand NB or PL (e.g. Lurpak Lighter Spreadable was substituted by Anchor Lighter Spreadable or by the private label option). In the same brand condition, we allocated substitutes within the same brand assortments. As there is a wide variety of cereals flavours within the same brand, we paired the products with similar healthiness/tastiness aspect using the categorisation from the UK National Health Service (NHS) ${ }^{2}$ and the availability in the supermarket assortment (e.g. Family cereals and Healthier cereals). For example, the same brand substitution for Kellogg's Special K can be Kellogg's Cornflakes as they are different in flavour but within the healthier cereals group. Matching with past purchase was conducted as a posterior measure. The final parts include survey questions which capture perceived fairness and demographic data.

\section{Results}

The result shows, in line with our expectations, an opposing trend for both categories: the majority of margarine buyers is more likely to accept a substitution alternative when it is of the same brand (65\%) than when it has the same flavour $(56 \%)$, while cereals buyers seem more likely to accept the substitution that is of the same flavour $(41 \%)$ rather than the one that is of the same brand $(21 \%)$. The difference in dominant attribute across these two categories is in line with observations from prior research where consumers in these two categories made a own choice of a replacement item for an OOS item in a physical store context (Campo et al., 2003). Checking the acceptance rate within the subset of same flavour substitution, margarine shoppers seem to be more likely to accept NB than PL flavour substitution (58.70\% vs. 47.80\%), while cereal shoppers have higher acceptance rate for PL than for NB flavour substitution (44.50\% vs. 39.50\%). The results on past purchase matching show, again in line with the expectations, that most respondents in both categories accept a substitution alternative that matches with what they have bought in the past 12 months compared to non-matching alternatives ( $84 \%$ vs. $50 \%$ for margarine; $64 \%$ vs. $29 \%$ for cereals).

In the binary logit model where we test the effects of the substitution policy, we control for price difference between a substitute and OOS item as well as household purchase frequency both of which are expected to have impact on the probability of acceptance (Campo et al., 2000, Xia et al., 2004). The main effect of the dominant attribute policy using same flavour substitution (vs. same brand) shows a negative coefficient in the margarine category $(\beta \mathrm{m}=-.452, \mathrm{p}=.013)$ while a strong positive coefficient is observed in the cereal category $(\beta c=1.126, p=.000)$. This confirms H1a,b. If we focus on flavour substitution only (so reducing the data to this subset only), we find the opposite reaction between margarine and cereals: an NB flavour substitution (vs. PL flavour substitution) returns a positive (negative) coefficient in the margarine (cereal) category $(\beta \mathrm{m}=.391, \mathrm{p}=.097 ; \beta \mathrm{c}=-.850, \mathrm{p}=.001)$, supporting $\mathrm{H} 2 \mathrm{a}, \mathrm{b}$ be it at the $10 \%$ level.

As to the policy where the retailer matches on whether products were bought in the past, we found that buyers in both categories positively reacted to substitutes that match one of their past purchased items in the same category $(\beta m=1.675, p=.000 ; \beta c=1.631, p=.000)$. This confirms H3 and suggests that when consumers have had an experience with the product in the past, matching substitute product to their past purchased item will significantly increase the probability

${ }^{2}$ NHS Eat well. Fat. https://www.nhs.uk/live-well/eat-well/different-fats-nutrition/

NHS Eat well. Sugar. https://www.nhs.uk/live-well/eat-well/how-does-sugar-in-our-diet-affect-our-health/ 
of the substitution being accepted. Turning to the interaction between the past purchase policy and the dominant attribute policy, we find no significant interaction in the margarine category, as expected in H4b, while a positive significant interaction was observed in the cereal category $\left(\beta \mathrm{m}_{\text {(past purchase } \mathrm{x} \text { same flavour) }}=.495, \mathrm{p}=.381 ; \beta \mathrm{c}_{(\text {past purchase } \mathrm{x} \text { same flavour) }}=.797\right.$, $\mathrm{p}=.041$ ), as expected in H4a. This suggests that past purchase matters more for HD than for VD category.

To test the mediating effects of perceived fairness, we apply the PROCESS bootstrapping mediation computation method proposed by Hayes (2017). The results are in support of H5, showing significant mediating effects of perceived fairness on the effects of the two substitution policies on the probability of acceptance of substitutes across two product categories. We find evidence for full mediation on the dominant attribute policy in the margarine category while partial mediation is observed in the cereals category. This suggests a higher sensitivity of fairness when switching brand in the VD category like margarine.

\section{Conclusion}

Using a computer-simulated experiment of a representative sample of UK consumers, we test the effectiveness of two types of substitution policies in the context of post purchase OOS in online grocery retailing. In contrast to the previous research's claim that most shoppers when facing OOS at the point of purchase either in store or online would tend to buy a replacement item straightaway rather than dropping the purchase (Campo et al., 2000, Sloot et al., 2005), our findings show the acceptance rate of cereal substitution ranges from $21 \%$ to $64 \%$ for cereals and from $48 \%$ to $84 \%$ for margarine, depending on the substitution policies - indicating that substitution policies matter. Indeed, implementing a suitable policy could increase the acceptance rate by $43 \%$ in cereals and $36 \%$ in margarine.

This study contributes to the online grocery retailing and substitution literature in several ways. First, to the best of our knowledge, this is the first study to investigate post-purchase OOS responses where retailers are in the position to select a substitution alternative to compensate for the inconvenience that an OOS generates. In the context of growing significance of online grocery retailing, our findings offer valuable insight to retailers in developing a suitable substitution strategy. Second, the post-purchase OOS context enables the advancement of a theoretical and managerial understanding of the role product attributes (brand vs. flavour) and category differentiation type (VD and HD) play in substitution decision. Existing literature have often studied these two concepts separately and our study by bringing them together has enabled a better understanding of OOS response. As demonstrated by Gabel et al. (2019), retailers could use data analytics and machine learning to identify dominant attributes in a category. Third, our study also offers an insight into how online retailers could use their knowledge of consumers' historical purchase portfolio to assist substitution decision. Although the use of past purchase in predicting behaviour has been commonly used in previous studies, none has examined consumers' past purchase as retailers' strategy to mitigate OOS response, which is especially pertinent given our online store context. Fourth, previous studies have flagged up the issue of consumers reactance to retailers' product recommendation in an OOS situation (Fitzsimons and Lehmann, 2004, Breugelmans et al., 2006) but have not explained the underlying mechanism of such reactance. We include perceived fairness as the mediating variable, which is not studied in previous research, to provide further understanding of the underlying mechanisms. Last, but not least, the method employed by our study - using computer-simulated shopping experiment on a large representative sample of UK consumers - increases the realism and generalisability of the research result compared to survey or scan data methods used in previous research.

\section{References}

Arens, Z. G. and Hamilton, R. W. (2016), Why Focusing on the Similarity of Substitutes Leaves a Lot to Be Desired. Journal of Consumer Research, Vol. 43 No. 3, pp. 448-459.

Batra, R., Homer, P. M. and Kahle, L. R. (2001), Values, Susceptibility to Normative Influence, and Attribute Importance Weights: A Nomological Analysis. Journal of Consumer Psychology, Vol. 11 No. 2, pp. 115-128.

Breugelmans, E., Campo, K. and Gijsbrechts, E. (2006), Opportunities for active stock-out management in online stores: The impact of the stock-out policy on online stock-out reactions. Journal of Retailing, Vol. 82 No. 3, pp. $215-228$.

Breugelmans, E., Campo, K. and Gijsbrechts, E. (2007), Shelf sequence and proximity effects on online grocery choices. Marketing Letters, Vol. 18 No. 1-2, pp. 117-133.

Bronnenberg, B. J. and Vanhonacker, W. R. (1996), Limited choice sets, local price response and implied measures of price competition. Journal of Marketing Research, Vol. 33 No. 2, pp. 163-173.

Campo, K., Gijsbrechts, E. and Nisol, P. (2000), Towards understanding consumer response to stock-outs. Journal of Retailing, Vol. 76 No. 2, pp. 219-242.

Campo, K., Gijsbrechts, E. and Nisol, P. (2003), The impact of retailer stockouts on whether, how much, and what to buy. International Journal of Research in Marketing, Vol. 20 No. 3, pp. 273-286.

CBinsights (2018), Private Labels Rising: How Retailer's Own Products Are Taking Off And Transforming The CPG Industry. CBinsights, available at: https://www.cbinsights.com/research/private-labels-disrupt-cpg-retail/, (accessed Choi, S. C. and Coughlan, A. T. (2006), Private label positioning: Quality versus feature differentiation from the national brand. Journal of Retailing, Vol. 82 No. 2, pp. 79-93.

Cocozza, P. (2019), Are these the worst supermarket substitutions ever? The Guardian, available at: https://www.theguardian.com/lifeandstyle/shortcuts/2019/may/08/are-these-the-worst-supermarket-substitutions-ever, (accessed 05 Aug 2019)

Deutsch, M. (1985), Distributive justice: A social-psychological perspective, Yale University Press, New Haven, CT: 
Dhar, R. (1997), Consumer Preference for a No-Choice Option. Journal of Consumer Research, Vol. 24 No. 2 , pp. $215-$ 231.

Drewnowski, A. (1997), Taste Preferences and Food Intake. Annual Review of Nutrition, Vol. 17 No. 1, pp. $237-253$. Etgar, M. and Malhotra, N. K. (1981), Determinants of Price Dependency: Personal and Perceptual Factors. Journal of Consumer Research, Vol. 8 No. 2, pp. 217-222.

Fitzsimons, G. J. (2000), Consumer response to stockouts. Journal of Consumer Research, Vol. 27 No. 2, pp. $249-266$. Fitzsimons, G. J. and Lehmann, D. R. (2004), Reactance to Recommendations: When Unsolicited Advice Yields Contrary Responses. Marketing Science, Vol. 23 No. 1, pp. 82-94.

Gabel, S., Guhl, D. and Klapper, D. (2019), P2V-MAP: Mapping Market Structures for Large Retail Assortments. Journal of Marketing Research (JMR), Vol. 56 No. 4, pp. 557-580.

Geyskens, I., Gielens, K. and Gijsbrechts, E. (2010), Proliferating Private-Label Portfolios: How Introducing Economy and Premium Private Labels Influences Brand Choice. Journal of Marketing Research, Vol. 47 No. 5, pp. $791-807$. Grewal, D., Roggeveen, A. L. and Tsiros, M. (2008), The Effect of Compensation on Repurchase Intentions in Service Recovery. Journal of Retailing, Vol. 84 No. 4, pp. 424-434.

Hamilton, R. W., Thompson, D. V., Arens, Z. G., Blanchard, S. J., Häubl, G., Kannan, P. K., Khan, U., Lehmann, D. R., Meloy, M. G., Roese, N. J. and Thomas, M. (2014), Consumer substitution decisions: An integrative framework.

Marketing Letters, Vol. 25 No. 3, pp. 305-317.

Hauser, J. R. and Shugan, S. M. (1983), Defensive Marketing Strategies. Marketing Science, Vol. 2 No. 4 , pp. 319. Hoeffler, S. and Ariely, D. (1999), Constructing stable preferences: A look into dimensions of experience and their impact on preference stability. Journal of Consumer Psychology, Vol. 8 No. 2, pp. 113-139.

Hotelling, H. (1929), Stability in Competition. Economic Journal, Vol. No., pp. 41-57.

Lind, E. A. (1995), Justice and authority relations in organisations, Kacmar, K. M. \& Cropanzano, R. (eds.),

Organisational Politics, Justice, and Support: Managing the Social Climate, Greenwood Publishing Group, Westport, Connecticut, pp.83-96

Mintel (2017a), Online Grocery Retailing UK - March 2017. Mintel, Online

Mintel (2017b), Yellow Fats and Edible Oils - UK - 2017. Mintel Group Ltd., London

Mintel (2018), Breakfast Cereals - UK - 2018. Mintel Group Ltd., London

Onwezen, M. C., Reinders, M. J., van der Lans, I. A., Sijtsema, S. J., Jasiulewicz, A., Guardia, M. D. and Guerrero, L. (2012), A cross-national consumer segmentation based on food benefits: The link with consumption situations and food perceptions. Food Quality and Preference, Vol. 24 No. 2, pp. 276-286.

Orchant, R. (2013), Best Butter Taste Test: Can You Tell The Difference Between Cheap And Expensive? Huffington Post, available at: http://www.huffingtonpost.com/2013/05/31/best-butter-taste-test-cheap-expensive n 3361785.html, (accessed 02 September 2017)

Poulter, S. (2011). It's back to the shops! Why we're fed up with buying groceries online. The Daily Mail, 21 June 2011. Pratkanis, A. R. and Farquhar, P. H. (1992), A brief history of research on phantom alternatives: Evidence for seven empirical generalizations about phantoms. Basic and applied social psychology, Vol. 13 No. 1, pp. 103-122.

Render, B. and O'Connor, T. S. (1976), The influence of price, store name, and brand name on perception of product quality. Journal of the Academy of Marketing Science, Vol. 4 No. 4, pp. 722-730.

Roberts, J. H. and Lattin, J. M. (1991), Development and Testing of a Model of Consideration Set Composition. Journal of Marketing Research (JMR), Vol. 28 No. 4, pp. 429-440.

Sayman, S., Hoch, S. J. and Raju, J. S. (2002), Positioning of Store Brands. Marketing Science, Vol. 21 No. 4, pp. 378397.

Severs, J. (2014). Analysis: Breaking down the barriers of online retail RetailWeek, September 302014.

Shao, X.-F. (2015), Product differentiation design under sequential consumer choice process. International Journal of Production Research, Vol. 53 No. 8, pp. 2342-2364.

Sloot, L. M., Verhoef, P. C. and Franses, P. H. (2005), The impact of brand equity and the hedonic level of products on consumer stock-out reactions. Journal of Retailing, Vol. 81 No. 1, pp. 15-34.

Smith, A. K., Bolton, R. N. and Wagner, J. (1999), A Model of Customer Satisfaction with Service Encounters Involving Failure and Recovery. Journal of Marketing Research (JMR), Vol. 36 No. 3, pp. 356-372.

Spiller, S. A. and Belogolova, L. (2017), On Consumer Beliefs about Quality and Taste. Journal of Consumer Research, Vol. 43 No. 6, pp. 970-991.

Tversky, A. (1977), Features of similarity. Psychological review, Vol. 84 No. 4, pp. 327-352.

Wedel, M., Vriens, M., Bijmolt, T. H. A., Krijnen, W. and Leeflang, P. S. H. (1998), Assessing the effects of abstract attributes and brand familiarity in conjoint choice experiments. International Journal of Research in Marketing, Vol. 15 No. 1, pp. 71-78.

Xia, L., Monroe, K. B. and Cox, J. L. (2004), The Price Is Unfair! A Conceptual Framework of Price Fairness Perceptions. Journal of Marketing, Vol. 68 No. 4, pp. 1-15. 